\title{
Modern high-resistance alloy steel used in railway transport
}

The article presents an overview of modern steel used in rail transport. Directions for the development of materials, technologies and constructions used in the manufacture of rail vehicles are, on the one hand, determined by the technical and economic requirements of industry and, on the other, by the continued emphasis of environmentalists on reducing fuel consumption and $\mathrm{CO}_{2}$ emissions. This generates innovation in the use of modern materials, processing methods and new design solutions and results in reduced vehicle weight. More bold forecasts today show that at the current pace of technology development, in the near future the mass of the vehicle will reduce by an average of $30 \%$.

Observing the trends and pace of rail transport development, it can be predicted that existing restrictions on the use of modern materials, such as high prices, technological conditions and difficult automation of large-scale production, can be predicted.

Key words: construction materials, constantly high strength, rail transport, new metals

\section{Introduction}

Similarly to other modes of transport, railway is characterized with certain features that underlie its specificity. Due to the nature of the impact on the functioning and advancement of this mode of transport, its individual characteristics can be divided into stimulating and destimulating ones. Among the properties that positively influence this mode of transport we may include:

- capability of carriage of great mass of cargo at a time (both in terms of weight of a single load and the total weight of the entire train);

- capability of carriage of a high number of passengers at a time (long distance routes - depending on the class of the compartment - from 54 to 72 seats in a single car, regional trains up to approx. 280 seats in a multiple train set or even more in multiple sets);

- capability of carriage of goods and passengers on long distance routes;

- limited negative impact on the natural environment in terms of energy consumption and exhaust emissions [1].

In Poland, railway transport can be divided into three basic subsystems: inter-agglomeration, regional and inagglomeration transit. It is assumed that the aim of the application of modern technologies in railway transport is to stop the current trend of reduced share of railway in the transport market and to lead to a sustainable development, i.e. ensuring maximum possible utilization of railway for carriage purposes, to which it is best designed.

The formation of self-government railway business entities, particularly the appearance of private companies on the market interested in providing transport services in railway regional passenger carriage is a symptom that this activity may turn out economically attractive and that it may thrive under the condition of stable, long-term financing of the initial deficit generated by this activity (Fig.1). The chances for development are the greatest in the area of agglomeration transport due to a competitive advantage over other modes of transport.

Following the analysis of the current condition of railway transport in Poland along with the SWOT analysis performed by the authors, it was observed that the most impactful decelerating factor is the degradation of infrastructure. The consequence of this degradation is low maximum speeds on the majority of the railway network. In many cases the speeds are much lower than the original speeds that were once applicable. There are also many speed limits on the routes. Both, the reduced maximum speeds and the introduced speed limits make the traveling times significantly extended compared to the shortest times obtained historically. The planned actions aim at a substantial improvement of the infrastructure and, as a consequence, boost the competitiveness of railway transport by increasing the cruising speeds (Fig. 2) and using modern steel as the fundamental building material of modern railway vehicles. The above will lay foundations for the development of new quality of transport of passengers and cargo.

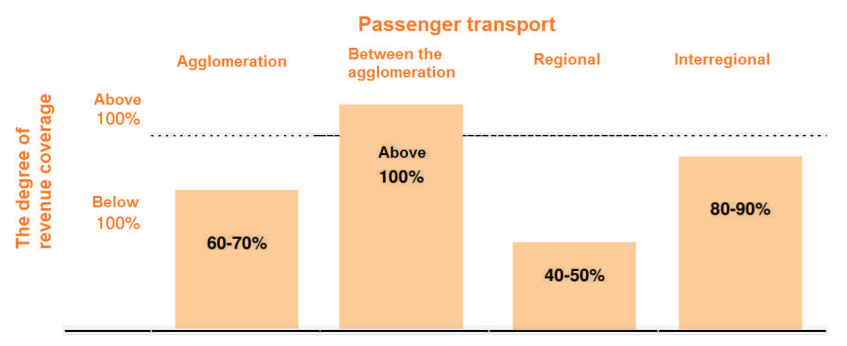

Fig. 1. Matrix of cost coverage with revenues in individual segments of the market of passenger carriage

\section{Analysis of strength and plasticity of metal sheets}

\subsection{Regulations}

The requirements of modern industry force a search for new building materials for production of metal sheets of high strength and good parameters in terms of technological plastification, allowing a reduction of the vehicle weight and rational energy consumption. A growing attention is drawn to low density alloys on the Aluminium (Al) and Magnesium (Mg) matrix and composite polymer plastics. The economic reasons and efficiency of recycling as well as the possibility of obtainment of a wide range of mechanical and technological properties result in metal sheets constituting over $65 \%$ of the vehicle weight. 


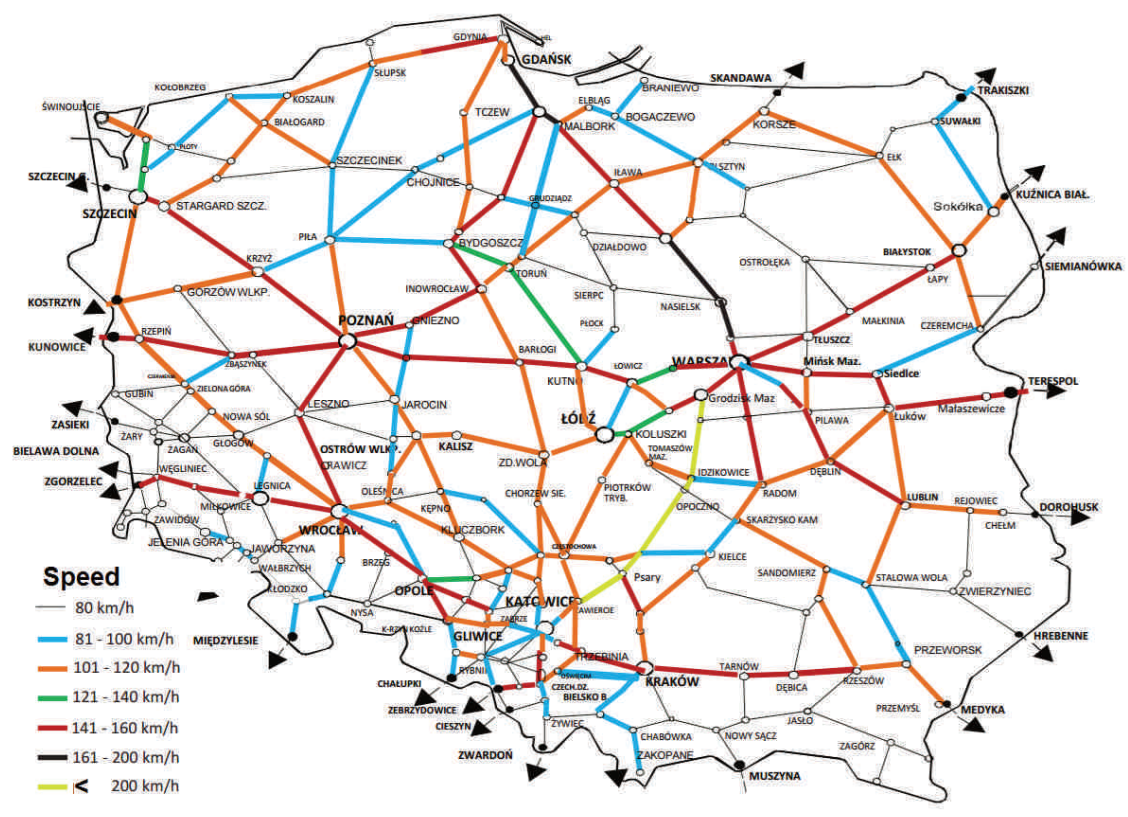

Fig. 2. Polish rail network and its maximum admissible speeds [3]

The last decade saw a rapid advancement in the development and production of modern steels used in transport for body and undercarriage components of railway vehicles. We may observe a dynamic development of high-strength types of steel that allow a reduction of the thickness of the applied steel metal sheets, hence the consumption of energy. Modern types of steel are characterized by multiphase microstructure that ensures a good balance between the strength properties and the plastic properties while the steel sheets are good in terms of technological plastification. In the further part of the paper, the authors analyze the principles of design of the chemical composition and microstructure of multiphase steels in the context of obtainment of the required mechanical and technological properties as well as final application of steel metal sheets in crucial loadbearing components of the tram bogies.

Currently, various types of deep drawn steel and HSLA steels are applied in the construction of railway vehicle bodies. The replacement of soft steels with steels of higher strength allows the application of thinner metal sheets. In fact, the weight of the railway carriages remains the same, as the reduction of mass resulting from the application of thinner high-strength metal sheets is compensated with additional equipment fitted to increase safety, comfort etc. A characteristic feature of conventional steels is the decreasing plasticity of sheets with the increasing strength (Fig. 3). An increase in the strength properties is relatively easy to obtain in a variety of ways: increased content of Carbon (C), increased hardenability by introducing alloy elements, solid solution strengthening, precipitation strengthening or deformation strengthening. The fundamental problem is to ensure the increased strength of metal sheets without a significant deterioration of plasticity. These requirements are met by modern types of highstrength DP, TRIP and CP steels of multiphase microstructure (Fig. 3). A significant contribution in the advancement of modern steel sheets for the industry was made by inter- national projects, in which numerous steel industry companies participated. The optimization of the weight of the body and the undercarriage became possible thanks to a complex application of steel of a good combination of strength and technological plasticity, modern methods of element forming and innovative technologies of joining individual body components.

The response of the material designers to the demand of the industry was the development of new groups of steels of a wide range of strength and plasticity related properties (Fig. $3)$. According to the nomenclature, these steels have been divided into three groups: LSS (Low-Strength Steels), HSS (High-Strength Steels) - steels of the plasticity boundary between 210 and $550 \mathrm{MPa}$ and tensile strength between 270 and $700 \mathrm{MPa}$, and UHSS (Ultra High-Strength Steels) [4].

Along with the increase in the share of the hard structural component, i.e. perlite, bainite, martensite, the strength properties increase and the plastic properties decrease (Fig. 3).

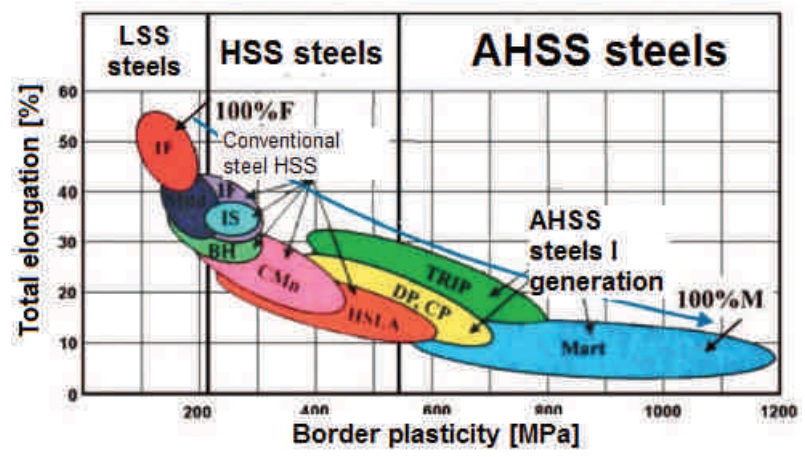

Fig. 3. Comparison of the mechanical properties of conventional HSS steels and modern AHSS steels used in transport [2]

A slightly higher plasticity (than that resulting from the parabolic trend line) have DP, CP and TRIP steels from the 
group of AHSS (Advanced High Strength Steels) of the first generation. The AHSS steels are defined as multiphase steels of the tensile strength of $\mathrm{Rm}$ greater than $500 \mathrm{MPa}$ and contain different shares of ferrite, bainite, martensite and residual austenite. They are marked as XX aaa/bbb, which denotes the type of steel and minimum $\mathrm{Re}$ and $\mathrm{Rm}$ values. For example, DP 350/600 denotes a dual phase steel of the minimum plastic boundary of $350 \mathrm{MPa}$ and the tensile strength of $600 \mathrm{MPa}$. The interaction among the structural components of different properties is the reason for good results in deformation strengthening, which distinguishes the AHSS steels from conventional HSS steels. These steels have been briefly described below. Only modern types of high-strength multiphase steels (AHSS) will be subject to analysis.

Conventional deep drawn mild steels are the most frequently applied deep drawn steels in the automotive industry for a variety of body closing components. Depending on the carbon content $(0.02-0.12 \%)$ they have different drawing class. Aside from impurities Sulphur (S) and Phosphorus $(\mathrm{P})$ they contain only carbon and from 0.25 to $0.6 \%$ Manganese (Mn). They are most often made as cold rolled steels and annealed in top hat furnaces or are subject to lengthwise annealing. The obtained tensile strength range is from 270 to $400 \mathrm{MPa}$ and the total extension - from 40 to $28 \%$. The main parameters characterizing the drawability of steels are the coefficient of normal anisotropy $r$ and the deformation strengthening exponent $\mathrm{n}[7,8]$.

IF (Interstitial Free) steels. These steels contain a minimum amount of Carbon $(\mathrm{C})$ and Nitrogen $(\mathrm{N})$ internodal elements $(\sim 0.003 \%)$, silicon and approx. $0.02 \% \mathrm{Nb}$ and/or $0.02 \%$ Ti that fully bond Nitrogen $(\mathrm{N})$ and Carbon $(\mathrm{C})$ in stable carbonitrides. From the analysis of Fig. 4, it results that they exhibit the highest plasticity out of all steels and extremely good deep drawability. Ultra low carbon and nitrogen content is obtained following a vacuum degasification. The mechanical properties of deep drawn steels (IF) are characterized by the effective plasticity boundary Rp0.2 from 140 to $220 \mathrm{MPa}$, tensile strength Rm from 230 to 300 $\mathrm{MPa}$, extension A from 37 to $50 \%$ and the coefficient of normal anisotropy up to 2.4 .

\subsection{Analysis of conventional high-strength steels}

HS-IF (High-Strength Interstitial Free) steels. These are IF type steels additionally solution-strengthened by an increased concentration of Phosphorus (P) (up to $0.03 \%$ ), Boron (B) (up to $0.003 \%$ ) and Manganese (Mn) up to $1.2 \%$. Their tensile strength may reach $390 \mathrm{MPa}$. BH (Bake Hardenable) steels are siliconless steels, containing below $0.03 \%$ Carbon (C), $0.1-0.5 \%$ Manganese $(\mathrm{Mn})$ and up to $0.02 \%$ Niobium $(\mathrm{Nb})$, very often containing increased concentration $(0.03 \%)$ of Phosphorus $(\mathrm{P})$ resulting in an increased strength and coefficient of sheet normal anisotropy. Beside the strengthening during cold deformation, the vehicle components made from $\mathrm{BH}$ sheets (e.g. doors, trunk covers) are also strengthened during paint curing, usually taking place at the temperature of $170^{\circ} \mathrm{C}$ for $20 \mathrm{~min}$, thus, boosting the plasticity and strength boundary by approx. 20-40 MPa. The idea behind this strengthening is the increase in the density of dislocation after the process of deep drawing and segregation of atoms of carbon in the paint- curing process. BH steel sheets are characterized by plasticity boundary Rp0.2 from 180 to $240 \mathrm{MPa}$, tensile strength Rm from 310 to $360 \mathrm{MPa}$, extension A from 42 to $36 \%$ and the coefficient of normal anisotropy of approx. 1.6. IS (Isotropic) steels have a chemical composition and mechanical properties that are similar to the HS-IF steel (Fig. 3). They are characterized by a ferritic microstructure and their coefficient of planar anisotropy is $\Delta \mathrm{r}=0$. This means that steel sheets exhibit isotropic properties during drawing, which allows an obtainment of a molding without the characteristic 'ears'. Carbon (C)-Manganese (Mn) steels are classic steels of mass usage of the ferritic-perlitic microstructure, usually containing below $0.1 \%$ Carbon $(\mathrm{C})$ and up to $1.5 \%$ Manganese (Mn) [6, 8].

\subsection{HSLA (high strength low alloy) steel analysis}

HSL steels are steels originating from the Carbon (C)Manganese $(\mathrm{Mn})$ steels. They contain micro-additives of high affinity to carbon and nitrogen, i.e. of the content of Niobium (Nb), Titanium (Ti), Vanadium (V) below $0.1 \%$. Metallic elements form dispersive particles of carbonitrides with Carbon (C) and Nitrogen (N) during hot plastic processing, precipitation-strengthening the steel and limiting the growth of austenitic grains during hot plate rolling, thus enabling the obtainment of fine-grained structure of the product.

Modern multiphase high-strength steels - the schematic presentation of the microstructure of modern types of multiphase high-strength steels has been shown in Fig. 4 that also presents the approximate range of extension and tensile strength, obtained by individual groups of steel. In reality, it is possible to obtain a very wide range of mechanical properties depending on the applied production technology, thermal processing parameters etc. Table 1 presents the chemical composition of typical multiphase steels.

DP (Dual Phase) steels - these are dual phase steels, in which small islands of martensite are evenly distributed in the ferrite matrix (Fig. 4) and the share of martensite is usually 15 to $30 \%$. The content of carbon in the steel is 0.05 to $0.18 \%$, silicon - from 0.1 to $0.6 \%$ and Manganese $(\mathrm{Mn})$ - from 1 to $2 \%$.

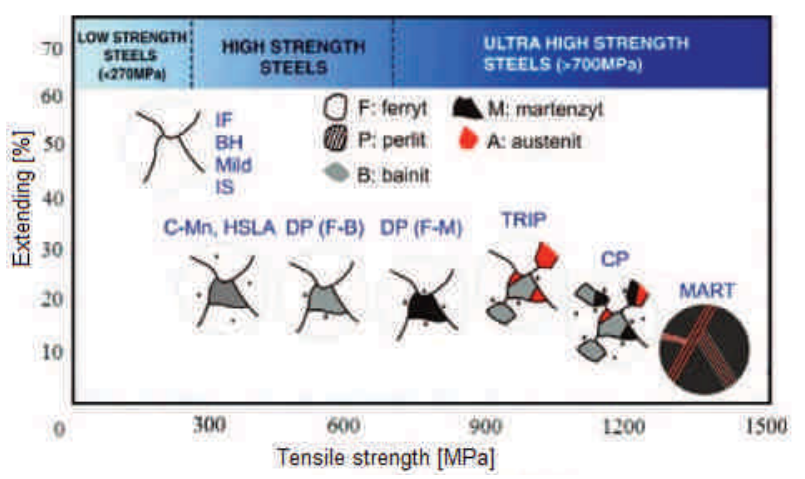

Fig. 4. Schematic presentation of the microstructure of different types of conventional and multiphase steels in transport [6]

Very often, in order to improve the hardenability, Chromium (Cr) and Molybdenum (Mo) are applied (1, 6, 7). The properties of dual phase steels depend on the share, 
hardness and distribution of martensite as well as on the ferrite hardness and distribution of its grains. They behave like a composite material, in which ferrite constitutes the matrix guaranteeing good plastic properties while martensite is the component that increase the strength. The ferritic martensitic structure can be obtained either through thermal processing of steel sheets after cold rolling or through the application of controlled chilling immediately after completion of hot rolling. A characteristic feature of DP steels is the lack of a clear plasticity boundary (lower and upper) and the Lüders deformation on the extension curve. These features are particularly important for metal sheet subject to drawing as well as other operations of technological forming. In the final stage of the thermal processing of metal sheets a martensitic transformation occurs of austenite distributed in the form of islands in the ferrite. During the martensitic transformation, which causes an increase in the volume, around the martensite occurs an area of compressive stress and new dislocations are generated (Fig. 5). It is important that these dislocations are capable of moving at the initial stage of plastic deformation, which explains the lack of clear plasticity boundary. The presence of hard islands of martensite is decisive of a deformation strengthening in the steel at the initial stage of plastic deformation, which delays the initiation of the sample narrowing in the tensile trial and thinning of the sheets during drawing. As a result, DP steels are characterized with a good combination of strength and drawability and a low value of the Rp0.2/ Rm quotient [5].

\subsection{TRIP (transformation induced plasticity) steels}

These are steels composed of the ferritic matrix, in which bainitic-austenitic islands are located. Typical TRIP steels contain $0.2 \%$ Carbon (C), 1.5\% Manganese (Mn) and $1.5 \%$ Silicon (Si) (Table 1).

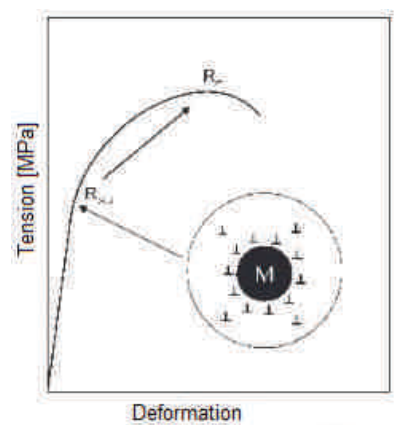

Fig. 5. Schematic presentation of the extension curve [5]

Such a combination of elements ensures the share of austenite on the level of 10 to $15 \%$, provided that the thermal processing was properly carried out. The presence of silicon has fundamental importance, as it slows down the precipitation of carbides during strength of the steel sheets in terms of bainitic transformation. In this way, carbon is not 'consumed' by carbides, but enriches the austenite to the content enabling a reduction of the temperature of the start of the martensitic transformation Ms below the room temperature, and, consequently, stabilization of the residual austenite. Unfortunately, Silicon (Si) generates problems during metal sheet galvanization, because the compounds forming on the surface do not ensure appropriate wettability of the sheets by liquid zinc. For this reason, steels containing Aluminium (Al) and/or Phosphorus (P) (Table 1) are also developed, which has a positive effect on the carbide inhibition (Fig. 7).

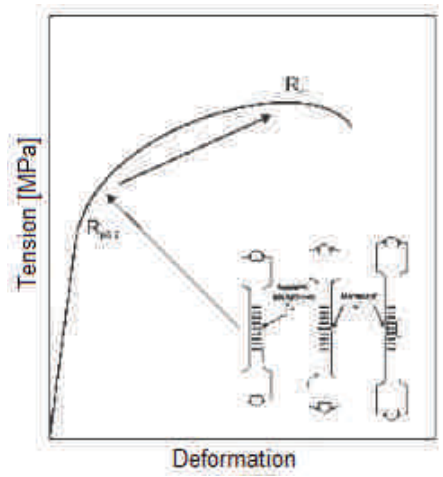

Fig. 6. Schematic presentation of the TRIP multiphase steel extension curve along with the schematics of deformation-induced martensitic transformation [5]

A characteristic feature of TRIP steels is the martensite transformation occurring during the sheet technological forming. The martensite transformation of residual austenite occurs gradually as the deformation increases. This transformation occurring in subsequent points of the molding prevents localization of the deformation and, at the same time, leads to heavy deformation strengthening (Fig. 6). This leads to a simultaneous increase of the $\mathrm{Rm}$ value and the delay of the initiation of the neck forming in the extension trial (and thinning of the sheet during drawing), thus leading to the obtainment of large even extension elongation evenly. A particularly beneficial combination of high-strength and plasticity is the main feature of multiphase TRIP steels [6, 7].

DP (F-B) (Ferritic-Bainitic) steels - these are dual phase steels containing bainitic islands instead of martensite (Fig. 2.2). A smaller difference in the hardness among the structural components, compared to the DP (F-M) steels, makes them particularly good for forming of the sheet edges and flanges and ensures good fatigue strength.

CP (Complex Phase) steels - these are steels containing fine-grained ferrite, bainite, martensite and residual austenite (Fig. 2.2). They are usually hot-rolled and additionally strengthened by dispersive particles of Niobium $(\mathrm{Nb})$ and Titanium (Ti). The increase in the steel hardenability is ensured by additions of Chromium ( $\mathrm{Cr}$ ) and Molybdenum (Mo) (Table 1). They exhibit particularly good energy absorption properties under dynamic loads.

HF (Hot-Formed) steels these are usually low-cost steels of the composition corresponding to 22MnB5 (Table $1)$. They are best for hot drawing of components of complicated shapes (B pillar, bumpers) and then press tempering. In the said processes a very good deformability of austenite is used, and the ready component has the properties corresponding to those of steel of tempered martensite. The components are protected against oxidation by Aluminium (Al) - Silicon (Si) layers. 


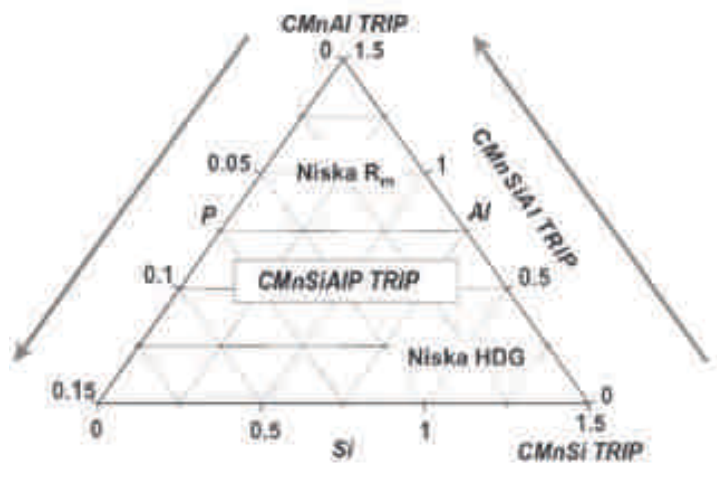

Fig. 7. The influence of the alloy elements on selected microstructural features and mechanical and technological properties of multiphase steels [6]

Table 1.Chemical composition of typical multiphase steels

$\begin{array}{cccccccc}\text { Type of steel } & \text { c } & \text { Mn } & \text { si } & \text { Al } & \text { Mo } & \text { cr } & \text { other } \\ \text { DP1 (F-M) } & 0,10 & 1,50 & 0,10 & - & - & 0,8 & \\ \text { DP2 (F-M) } & 0,10 & 1,50 & 0,25 & - & 0,15 & - & 0,1 \text { Ti. B } \\ \text { TRIP1 } & 0,20 & 1,50 & 1,50 & - & - & & \\ \text { TRIP2 } & 0,24 & 1,50 & 0,25 & 1,50 & 0,15 & - & \\ \text { DP3 (F-B) } & 0,07 & 0,80 & 0,50 & - & - & - & 0,03 \mathrm{NB} \\ \text { CP } & 0,15 & 1,50 & 0,25 & - & 0,20 & 0,30 & \text { T. Nb. B } \\ \text { HF } & 0,22 & 1,25 & 0,20 & - & - & & 0,003 \mathrm{~B} \\ \text { MART } & 0,05-0,2 & 1,50 & 0,20 & - & - & & \end{array}$

MART (Martensitic) steels - These are steels of the microstructure of martensite, sometimes containing a small share of bainite and/or residual austenite (Fig. 7). They are characterized by the best strength properties that mainly depend on the carbon content in the steel. Due to the extension lower than $10 \%$, their plastic deformation is possible only when rolled.

\section{Conclusions}

The development trends in material technologies and designs applied in the production of railway vehicles are deter- mined by the technical and economic requirements imposed by the industry as well as a continuous pressure of environmentalists regarding the reduction of fuel consumption and the emissions of $\mathrm{CO}_{2}$. This spurs innovativeness in the application of modern materials, methods of their processing and in novel design solutions and reduces the weight of the vehicles. More daring forecasts hail that, at the current technology advancement rate, in the nearest future the weight of a vehicle will be reduced by $30 \%$ on average.

A very important aspect in the process of design and application of modern materials is the system of recycling of used vehicles. The manufactures of the rolling stock when designing their vehicles must allow for the need to recycle the vehicle at the end of its life cycle. This is observed through the application of recyclable materials, marking of the materials and proper material combinations (the latter will facilitate its later dismantling and segregation of material fractions). By doing so, the rolling stock recyclability index may reach up to $95 \%$, similarly to onroad vehicles. The actual recyclability index will depend on many factors such as the existing infrastructure of material recycling facilities, availability of recycling technologies (particularly modern materials), demand for recycled materials and parts for reuse, legislation imposed on business entities with a view to obtaining certain recyclability levels as well as the expectations and environment related policy of the rolling stock operators [2].

When observing the trends and the advancement of the railway transport, we may fore-cast that there still exist limitations as to the application of modern materials (high price, technological specificity, difficult automation of serial production). Looking at the automotive market, however, it appears these limitations are soon to be overcome.

\section{Bibliography}

[1] HOLTZER, M. Procesy metalurgiczne i odlewnicze stopów żelaza., Wydawnictwo Naukowe PWN. Warszawa 2013.

[2] KORZYŃSKI, M. Nonconventional finishing technologies. Wydawnictwo Naukowe PWN. Warszawa 2013.

[3] LIPIŃSKI, T., WACH, A. The effect of fine non-metallic inclusions on the fatigue strength of structural steel. Archives of metallurgy and materials. 2015, 60(1).

[4] MERKISZ-GURANOWSKA, A., DASZKIEWICZ, P., MERKISZ, J. et al. Zrównoważona polityka odzysku materiałów

\begin{abstract}
Włodzimierz Stawecki, Ph.D. - Managing Director of the Rail Vehicles Institute TABOR in Poznan. e-mail: Sekretariat@tabor.com.pl
\end{abstract}

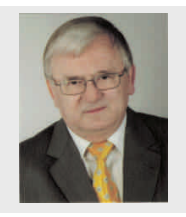

Maciej Bajerlein, DSc., DEng. - Faculty of Machines and Transport at Poznan University of Technology.

e-mail: Maciej.Bajerlein@put.poznan.pl

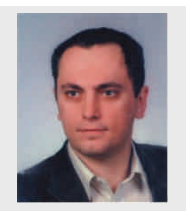

z taboru kolejowego wycofanego z eksploatacji. Najnowsze technologie w transporcie szynowym. Józefów 2014.

[5] PIETRZAK, K., PIETRZAK, O. Ekonomiczne i organizacyjne aspekty transportu kolejowego. Bydgoszcz 2013.

[6]. ROGAL, Ł., KORPAŁA, G., DUTKIEWICZ, J. Evolution of microstructure in $100 \mathrm{Cr} 6$ steel after cooling from a thixoforming temperature to bainitic transformation ranges. Materials science and engineering a-structural materials properties microstructure and processing. 2015, 624.

[7] Master plan dla transportu kolejowego w Polsce do 2030 roku. Ministerstwo Nauki i Szkolnictwa Wyższego.

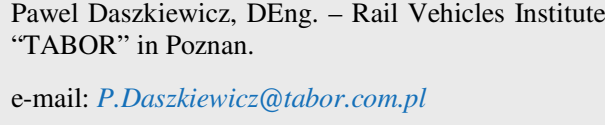

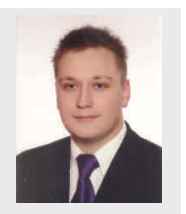

